\title{
Effects of Goal Appraisals and Goal Motivation on Dimensions of Identity Development: A Longitudinal Mixed Methods Analysis of European American Emerging Adults
}

\author{
Kathryn Mulvihill ${ }^{1}$. E. Gaëlle Hortop ${ }^{2}$. Maude Guilmette ${ }^{3}$ - Erin T. Barker ${ }^{1}$. Diane L. Putnick ${ }^{4}$. \\ Marc H. Bornstein ${ }^{4,5,6}$
}

Accepted: 6 June 2021 / Published online: 23 July 2021

(c) Springer Science+Business Media, LLC, part of Springer Nature 2021

\begin{abstract}
In the present study, we investigated the ways in which the ideographic goal descriptions and goal appraisals of European American high school seniors reflect potentials for intentional self-development during emerging adulthood (EA), a lifespan phase characterized by increasing levels of freedom and decreasing age-graded, socially sanctioned developmental norms. Additionally, we investigated whether variation in participants' goal appraisals and the motivational qualities emergent in their goal descriptions would predict variation in dimensions of identity development, both concurrently at age 18 and prospectively at age 23 . Results of an exploratory, mixed method analysis of participants' $\left(N=129,56.6 \%\right.$ male, $M_{\text {age }}=18.24$, $\mathrm{SD}=0.37)$ goal data revealed diversity in education and work goals, strong potentials for intentional self-development reflected across goal appraisals, and more nuanced reflections of intentional self-development across the motivational qualities emergent in goal descriptions. Results partially supported the hypothesis that goal appraisals and motivational qualities that reflect potentials for intentional self-development would predict kindred processes of identity development across the first five years of EA. These findings contribute to a nascent empirical literature focused on the interrelationship of goal and identity constructs during EA and suggest new avenues for future research.
\end{abstract}

Keywords Emerging adulthood $\cdot$ Goals $\cdot$ Identity development $\cdot$ Intentional self-development

Capacities for intentional self-development should help individuals to optimize their development during emerging adulthood (EA), a lifespan phase marked by increasing levels of freedom and decreasing levels of age-graded, socially sanctioned developmental norms. Processes of goal pursuit and processes of identity development have been conceptualized as key vehicles for intentional self-development in EA.

\footnotetext{
Kathryn Mulvihill

kate.mulvihill@gmail.com

Psychology, Concordia University, Montreal, QC, Canada

Psychology, University of Ottawa, Ottawa, ON, Canada

3 Psychology, Université du Québec à Montréal, Montreal, QC, Canada

4 Eunice Kennedy Shriver National Institute of Child Health and Human Development, Bethesda, MD, USA

5 Institute for Fiscal Studies, London, UK

6 UNICEF, New York City, USA
}

Additionally, a growing number of empirical studies indicate that goal pursuit processes that reflect intentional selfdevelopment (e.g., mastery goal orientation, intrinsic goal orientation, adaptive self-regulation of challenges) positively predict variation in kindred processes of identity development (Brandstätter \& Herrmann, 2016; Luyckx et al., 2017; Negru et al., 2013; Tao et al., 2018) and vice versa (Flunger et al., 2016; Luyckx et al., 2017; Milner \& Ferrari, 2010), suggesting that these processes may support one another in EA. One limitation of this literature is a lack of research exploring the ways in which the ideographic goals of emerging adults reflect potentials for intentional self-development. A second limitation is a lack of evidence for prospective effects of processes of goal pursuit on processes of identity development and vice versa. We addressed these limitations by collecting narrative descriptions of emerging adults' most important goals at age 18, exploring the ways in which these goal data reflected potentials for intentional self-development, and examining effects of the goal-related constructs 
we explored on dimensions of identity development across the first five years of EA.

\section{Intentional Self-Development in EA}

The theory of intentional self-development (Brandtstädter \& Lerner, 1999) proposes that individuals, though responsive to environmental influences, actively shape their own development across the lifespan through self-referential processes involving action and evolving internal representations of self and environment. According to this perspective (Brandtstädter, 2009; Brandtstädter \& Rothermund, 2002), the activities of intentional self-development are encompassed by two families of adaptive processes that unfold across the lifespan: assimilative processes, which aim to reduce discrepancies between actual and desired self-representations by modifying situations or one's own behavior, and accommodative processes, which aim to reduce such discrepancies through the modification of goals themselves. Overall, assimilative activities, which center on expanding resources and achieving normative standards or ideals of personal development, are thought to dominate during earlier adulthood, whereas accommodative processes, which involve rescaling, downgrading, or disengaging from blocked goals, are thought to become increasingly activated by irreversible losses of support and control in later adulthood (Brandtstädter, 2009).

Capacities for intentional self-development, particularly assimilative capacities, should help individuals to optimize their development during EA, the lifespan phase that begins at the end of adolescence and ends with the adoption of enduring adult roles (Arnett, 2000). Largely a result of the postponement of these roles, EA has been conceptualized as a time of unprecedented freedom in which individuals can search for relationships, work, and worldviews that fit their evolving sense of self and, hence, support their success and well-being (Arnett, 2014).Hand in hand with this freedom, however, comes the gradual erosion of age-graded, socially sanctioned norms that previously ushered youth across the transition to adulthood (Côté \& Bynner, 2008; Schwartz et al., 2005). Emerging adults who exercise assimilative capacities for intentional self-development are more likely, through activities aimed at expanding resources and skills, to take advantage of time-limited opportunities to explore. Further, such individuals are more likely, through activities aimed at achieving standards and ideals of personal development, to steer the course of their own lives in valued directions during a phase that offers few normative guidelines for development. If this is the case, then identifying mechanisms of intentional self-development during EA is an important task for developmental science.

\section{Two Key Vehicles for Intentional Self-Development in EA}

Two processes that have been conceptualized as key vehicles for intentional self-development in EA are processes of goal pursuit and processes of identity development. As the means by which individuals intentionally shape their own development across the life course (Brandtstädter, 1999; Heckhausen \& Tomasik, 2002; Nurmi, 1993), goals may be particularly important during EA due to its unstable and transitional nature (Shulman \& Nurmi, 2010). Previous research on the role of goals in EA aligns with this idea. For example, the average number of educational, friendship, and travel-related goals decreased while the average number of work, family, and health-related goals increased in the 10 years following Finnish emerging adults' first semester in university (Salmela-Aro et al., 2007), suggesting that participants intentionally shifted their goals in response to their transition to adulthood. Furthermore, having a greater number of family-related goals at the start of university predicts earlier transitions into marriage and parenthood, supporting the idea that self-identified goals can channel emerging adults into new developmental environments (Nurmi, 1993, 2004). Other research has shown that the importance and motivation emerging adults attach to their goals predict progress and likelihood of goal achievement, which could also presage self-directed transitions into new roles and environments (Heckhausen et al., 2013; Nurmi et al., 2002).

Identity development is widely regarded as the most important developmental task of EA (Nelson \& Barry, 2005; Roberts et al., 2004; Salmela-Aro, 2009; Shulman \& Nurmi, 2010). Differences in theoretical approach and emphasis notwithstanding, contemporary models of identity development that originate from Erikson's (1950) psychosocial theory and that extend and expand Marcia's (1966) operationalization of Eriksonian theory (identity status classification; Marcia, 1966), emphasize the importance of intentional, self-reflective participation in the process of identity development (Berzonsky, 1989; Crocetti et al., 2008a, 2008b; Luyckx et al., 2006). Indeed, when emerging adults seize opportunities to engage deeply in the process of identity development, their trajectories are more likely to be characterized by what Côté referred to as developmental individualization (Côté, 2002; Schwartz et al., 2005)_increasing differentiation in the life course that is defined by deliberate, ongoing growth. 


\section{Linking Processes of Goal Pursuit and Processes of Identity Development in EA}

Theorists have advanced various conceptualizations of the association between processes of goal pursuit and processes of identity development, some of which are specific to EA and others of which apply to lifespan development in general. Some of these conceptualizations emphasize that goal and identity processes are distinct, but interrelated aspects of a larger developmental phenomenon. For example, according to Erikson's psychosocial theory (Erikson, 1974, 1980; Schwartz, 2001), goals represent the personal level of identity, which lies between ego identity and social identity and serves to distinguish a person from others. Goals and identity (specifically, narrative identity) have also been conceptualized as distinct, but interrelated aspects of personality that emerge at different stages of development (McAdams \& Olson, 2010). In addition, self-regulation of goals and identity development have been conceptualized as interrelated aspects of an agentic meta-process by which emerging adults navigate the transition to adulthood (Dietrich et al., 2012; Marttinen et al., 2018). Other conceptualizations emphasize causal effects of goal-related constructs on identity-related constructs, and vice versa, during EA. For example, a clear, coherent set of goals has been conceptualized as an outcome of a healthy, or consolidated, identity (Crocetti et al., 2013). A healthy identity (i.e., the discovery of a true, authentic self), in turn, has been conceptualized as an outcome of pursuing certain kinds of goals (i.e., goals that facilitate personal expressiveness and experiences of flow; Waterman, 2011). Other theorists have proposed broadly that goals and goal regulation processes should influence how emerging adults conceptualize themselves and their identities, and that self-concepts and identities, in turn, should influence goal selection and self-regulation during EA (Shulman \& Nurmi, 2010), a formulation that is consistent with Brandtstädter and Lerner's (1999) notion of reciprocal processes of action and evolving working models of self and environment as key drivers of intentional self-development.

A growing empirical literature supports the idea that processes of goal pursuit and processes of identity development are interrelated and may influence one another during EA. Some of these integrative studies suggest that individual differences in motivational orientations towards goals (Luyckx et al., 2017; Negru et al., 2013; Tao et al., 2018) or in self-regulatory processes associated with challenging goal pursuit processes (Brandstätter \& Herrmann, 2016) may promote different processes of identity development among emerging adults. Other studies suggest that individual differences in dimensions of identity development, i.e., the ways in which emerging adults make decisions, solve problems, and process identity-relevant information, may influence motivational tendencies towards goals (Flunger et al., 2016; Luyckx et al., 2017; Milner \& Ferrari, 2010). And although each of these studies reveals complexity in the associations between the goal- and identity-related constructs under study, all nonetheless demonstrate positive associations between sets of constructs that reflect stronger potentials for intentional self-development in EA. For example, in two short-term longitudinal studies of Belgian first-year university students, Luyckx et al. (2017) examined associations between intrinsic and extrinsic goal orientations (Kasser \& Ryan, 1996) and the five dimensions of Luyckx et al.'s (2008) dual-process model of identity development. The results indicated that stronger tendencies to adopt intrinsic goals were associated with increases in adaptive commitment making processes (i.e., commitment making and identification with commitment) over time, whereas stronger tendencies to adopt extrinsic goals were associated with increases in ruminative exploration (Luyckx et al., 2017, Study 2).

\section{Limitations of Previous Research}

One limitation of the nascent literature linking processes of goal pursuit and processes of identity development in EA is a lack of research exploring the ways in which the ideographic goals of emerging adults reflect potentials for intentional self-development. Across the six studies reviewed above, four focused on goal constructs at the level of general, or global/dispositional orientations, such as those described by Elliot and McGregor's (2001) $2 \times 2$ achievement goals framework (Negru et al., 2013), Kasser and Ryan's (1996) distinction between intrinsic and extrinsic goal orientations (Luyckx et al., 2017; Tao et al., 2018), and Ames and Archer's (1988) achievement goal orientation model (Milner \& Ferrari, 2010). Furthermore, neither of the two studies that collected descriptions and appraisals of specific, ideographic goals (Brandstätter \& Herrmann, 2016; Flunger et al., 2016) described the contents of goals or attempted to characterize the extent to which the goal data itself reflected potentials for intentional self-development during EA. Given that the literature linking processes of goal pursuit and processes of identity development in EA is still "in its infancy" (Luyckx et al., 2017, p. 1765), exploring whether and how emerging adults' ideographic goal data reflect potentials for intentional self-development could provide rich, descriptive information with the potential to stimulate theory-building concerning the ways in which these sets of constructs relate to one another during EA.

Another limitation of this literature is a lack of evidence for prospective effects of either set of constructs on the other. Of the six studies reviewed above, three were cross sectional in nature (Milner \& Ferrari, 2010; Negru et al., 2013; Tao 
et al., 2018), and three employed a longitudinal design (Brandstätter \& Herrmann, 2016; Flunger et al., 2016; Luyckx et al., 2017). Of the three longitudinal studies, the study by Luyckx et al. (2017) demonstrated effects of intrinsic vs. extrinsic goal orientations on short-term changes in dimensions of identity development and vice versa. Likewise, the study by Brandstätter and Herrmann (2016) demonstrated effects of action crisis intensity on increases in appraisals of decisional certainty and desirability of post-disengagement goals, which were interpreted as indications of increases in identity stability. However, neither identity stability nor any other dimension of identity development was measured directly in this study, limiting the degree to which its findings can be cited as evidence consistent with causal effects of goal-related constructs on identity development constructs. Last, the study by Flunger et al. (2016), while revealing cross-sectional associations linking dimensions of identity development and goal appraisals with achievement goal orientations, found no evidence for effects of identity dimensions or goal appraisals on changes in achievement goal orientations over time. Longitudinal designs allow researchers to establish that variation in predictor variables precedes variation in outcome variables, a necessary criterion for limited causal inference in non-experimental studies (Bachman \& Schutt, 2013). Therefore, longitudinal studies that establish prospective effects of goal-related constructs on dimensions of identity development and vice versa, are needed to provide evidence consistent with the hypothesis that that these constructs influence one another during EA.

\section{The Present Study}

To address these limitations, we conducted a mixed methods, exploratory analysis of the contents, appraisals, and narrative descriptions of the ideographic education and work goals of European American students in their final semester of high school, focusing on constructs that reflected potentials for intentional self-development. We then examined effects of the goal constructs we studied on several dimensions of identity development. Multiple regression analyses tested the hypothesis that goal appraisals and motivational qualities reflecting intentional self-development would be positively related to dimensions of identity development that also reflect potentials for intentional self-development, and negatively related to dimensions that reflect difficulties with intentional self-development, both concurrently (at age 18) and prospectively (at age 23 ).

\section{Method}

\section{Participants}

Participants were part of an ongoing longitudinal cohort study of mother-child and family development funded by the Intramural Research Program of the Eunice Kennedy Shriver National Institute of Child Health and Human Development. Since its inception, this project has investigated patterns of development in social, psychological, and cognitive functioning from infancy through childhood, adolescence, and early emerging adulthood. The project has also investigated how parental relationships and family context relate to growth, stability, and continuity in core developmental processes by employing multivariate, multi-informant, multiwave approaches (e.g., Bornstein et al., 2019; Putnick et al., 2020). First-time mothers and their infant children were initially recruited from a metropolitan area on the East coast of the United States via mass mailings and newspaper advertisements. The initial sample was limited to European American families to facilitate the delineation of basic developmental processes for this group before making comparisons with other ethnic or cultural groups. Homogeneous convenience samples such as this allow for clear validity and generalizability in this regard (see Bornstein et al., 2013; Jager et al., 2017 for detailed discussions of developmental sampling approaches). The sample has since been used in multi-sample examinations of cross-cultural similarities and differences in various developmental processes (e.g., Cote et al., 2015; Karasik et al., 2015).

To be included in the current study, participants had to have provided a written description of their most important education and work goal, respectively, at the age 18 measurement occasion. Emerging adults meeting this criterion $\left(N=129,56.6 \%\right.$ male, $\left.M_{\text {age }}=18.24, \mathrm{SD}=0.37\right)$ were European American, first-born individuals from middle to upper-middle class (SES; Hollingshead, 1975, $M=57.04$, $\mathrm{SD}=7.52$, SES range $=35-66$ ), largely intact, two-parent (78\%) families who were completing their senior year of high school and, who, for the most part (96\%), were bound for university in the fall.

\section{Procedure}

At the age 18 (Time 1) and 23 (Time 2) measurement occasions, participants gave IRB-approved informed consent and completed online surveys for modest compensation. 


\section{Measures}

\section{Elicitation of Ideographic Goal Descriptions at Age 18}

At Time 1, participants' goal descriptions were collected using Personal Projects Analysis (PPA; Little, 1983), a flexible instrument that combines ideographic and nomothetic assessment approaches to the goal construct and can be adapted for specific research questions (Little \& Gee, 2007). First, participants were provided with a definition of personal projects: "Everyone has different types of goals, wishes, dreams, and projects in mind. We can think of these as personal projects. Personal projects can range from short term plans (buying a birthday present for a friend, taking a pet to the vet) to long term plans (writing a novel, finishing a 4-year college degree) or from mundane goals (stopping nail biting, remembering to make your bed) to life changing goals (starting to eat healthy and exercise, discovering your spiritual beliefs)." Next, participants were prompted to describe their most important education and most important work goal. No instructions were given concerning length, level of detail, or type of content.

\section{Goal Appraisals}

At Time 1, participants were asked to appraise their goals on dimensions of (i) importance, (ii) depth of involvement, (iii) likelihood of accomplishment, (iv) knowledge of how to achieve the goal, (v) capacity to achieve the goal, (vi) having the means to achieve the goal, and (vii) success to date. Higher ratings on each dimension can be conceptualized as reflecting stronger beliefs concerning goal importance (i.e., importance, depth of involvement) or goal attainability (i.e., likelihood of accomplishment, knowledge of how to achieve the goal, capacity to achieve the goal, having the means to achieve the goal, and success to date), which, according to theory and research on intentional self-development (Brandtstädter, 2009), are the two cognitive factors that most strongly support assimilative activities across the lifespan. Thus, we propose that stronger endorsement of each of these goal dimensions can be considered a potential for intentional self-development in EA. Participants used a 7-point scale $(0=$ not at all important, $3=$ somewhat important, $6=$ very important) to rate each dimension.

\section{Goal Coding}

Self-determination theory (SDT; Ryan \& Deci, 2017) research has shown that autonomous motivation for goals, as well as satisfaction of basic psychological needs for autonomy, competence, and relatedness related to processes of striving, are powerful predictors of goal-directed effort, persistence, and achievement (Deci \& Ryan, 2000;
Koestner et al., 2008; Sheldon, 2014). Thus, although not foregrounded by Brandtstädter's theory (2009), autonomous motivation and experiences of need satisfaction can be conceptualized as phenomena that promote assimilative activities, and, therefore, as additional potentials for intentional self-development during EA. With the possible exception of depth of involvement, the appraisal dimensions included in the PPA for the present study did not explicitly capture constructs related to autonomy or need satisfaction. Therefore, we conducted a qualitative analysis of participants' goal descriptions to code for the presence vs. absence of five additional goal characteristics with theoretical and empirical links to these constructs (autonomous motivation, intrinsic goal content, mastery goals, volitional phrasing, and distal temporal framing).

Self-determination theory defines autonomous motivation as motivation based on one's values, beliefs, and autotelic interests (Deci \& Ryan, 2000; Ryan \& Connell, 1989) and intrinsic goal content functionally as content whose pursuit produces experiences of need satisfaction (Deci \& Ryan, 2000; Kasser \& Ryan, 1996) independently of the extent to which the goal is autonomously motivated (Sheldon et al., 2004). Additionally, Chambers' (2007) linguistic classification system for personal projects defines volitional phrasing as simple, unqualified statements of intention (e.g., to do $X$ ), which reflect a higher degree of perceived competence and a lower degree of inner conflict concerning a chosen goal, which accord with principles of need satisfaction and volitional freedom. Similarly, the temporal framing of goals as distal, or goals for the far future (Weldon \& Yun, 2000), is thought to sustain intrinsic motivation for aspirations over time, a theory supported by previous research in which distal goals were related to higher levels of task orientation, excitement, and persistence (Simons et al., 2004). Finally, because the present study focused on descriptions of education and work goals, domains of striving in which competence is a central concern, we also coded for the presence vs. absence of mastery goals. According to the $2 \times 2$ achievement goals framework (Elliot \& McGregor, 2001), a mastery goal is one whose aim is attaining task-based requirements or selfimprovement. Theoretical (Vansteenkiste et al., 2014) and empirical (e.g., Rawsthorne \& Elliot, 1999; Sommet \& Elliot, 2017) evidence suggests that mastery goals overlap with, and may amplify the effects of, autonomous motivation on outcomes related to tenacious goal adherence and, thus, to assimilative activities of intentional self-development.

Goal descriptions were coded dichotomously for the presence (1) vs. absence (0) of each of these five additional constructs. Descriptions that did not reflect important personal goals, such as statements of current activity, (e.g., "I am a lifeguard over the summer...") and clichés and overgeneralizations, (e.g., "Learn everything there is to know") were assigned a code of 888 . Table 3 presents operational 
definitions developed by the first author to guide coding. After the first author coded all goal descriptions, 30 education and 30 work goal descriptions were coded for interrater reliability by the second author, who was blind to study hypotheses and all other study data, but familiar with goal theory. Both coders were blind to all information about the authors of the goal statements. The two coders achieved acceptable levels of inter-rater reliability (Table 3) and resolved discrepancies via discussion. Subsequent analyses were performed using the first author's codes. Examples of the coding procedures are available in an online supplemental file (S1).

\section{Indices of Potentials for Intentional Self-Development}

To create a composite that indexed the extent to which participants' goal appraisals reflected potentials for intentional self-development, we summed appraisal ratings across education and work goals. Likewise, to create a composite that indexed the extent to which the motivational qualities of participants' most important goals reflected potentials for intentional self-development, we summed qualitative codes across education and work goals. In creating both indices, we relied on and adapted the well-established method of summing appraisal ratings across goals to index a particular quality (e.g., Brunstein, 1993; Cantor et al., 1991; Emmons, 1986; Lecci et al., 1994; Little, 1989). This approach maximized statistical power in our quantitative analyses by reducing the number of potential predictors from 12 (seven appraisal dimensions and five motivational construct codes) to two (one appraisal index and one motivational qualities index).

\section{Dimensions of Identity Development}

At Times 1 and 2, dimensions of identity development were assessed with the ideological subscales of the Extended Objective Measure of Ego Identity Status II (EOM-EIS-II; Bennion \& Adams, 1986). Grounded in Erikson's (1950) psychosocial theory and Marcia's (1966) identity status framework, the EOM-EIS-II achievement subscale captures the extent to which respondents have made identity commitments following a period of active exploration and the moratorium subscale captures the extent to which participants are still actively exploring. These two subscales reflect potentials for intentional self-development in EA because they reflect current engagement in active, purposeful, and reasoned processes of exploring possible values, goals, and beliefs (Marttinen et al., 2018). In contrast, the EOM-EIS-II foreclosure subscale captures the extent to which respondents have made identity commitments in the absence of exploration and the diffusion subscale captures the extent to which respondents are neither committed nor actively exploring. These two subscales reflect difficulties with, or barriers to intentional self-development in EA in that they demonstrate uncritical acceptance or rigid adherence to external norms and directives, or aimlessness (Schwartz, 2001). Participants rated eight items for each subscale on a 6-point scale anchored at 1 (strongly disagree) and 6 (strongly agree). Sample items include, "It took me a while to figure it out, but now I really know what I want for a career (achievement)," "I'm still not sure about my political beliefs, but I'm trying to figure out what I can truly believe in (moratorium)," "My parents' views on life are good enough for me. I don't need anything else (foreclosure)," and "I haven't really considered politics. It just doesn't excite me much (diffusion)." A higher average across the eight items for each scale indicates a higher degree of the construct assessed. At Times 1 and 2, internal consistency reliabilities for the subscale scores were: achievement: $\alpha \mathrm{s}=.63, .63$; moratorium: $\alpha \mathrm{s}=.77, .73$; foreclosure: $\alpha \mathrm{s}=.79, .82$; diffusion: $\alpha \mathrm{s}=.62, .62$.

\section{Covariates}

\section{Word Count}

As no instructions were given vis-à-vis the length of education and work goal descriptions, whose descriptions varied considerably in length, we created a word count variable for each goal.

\section{Socioeconomic Status}

Socioeconomic status was measured with the Hollingshead Four-Factor Index of Socioeconomic Status (Adams \& Weakliem, 2011; Hollingshead, 1975).

\section{Results}

\section{Preliminary Analyses}

Descriptive analyses performed as part of our mixed methods exploratory analysis of participants' goal descriptions and appraisals were carried out in IBM SPSS Statistics, version 22 . To handle missing responses in bivariate correlation and multiple regression analyses, we used full maximum likelihood estimation algorithms associated with maximum likelihood (ML) estimation in Mplus version 7 (Muthén \& Muthén, 2017), which rely on missing at random assumptions (Asparouhov \& Muthén, 2010).Missing data were present only for the EOM-EIS-II scales at Time 1 (7.8-9.3\% across subscales) and Time 2 (26.4\% for each subscale, respectively). Participants who were missing vs. not missing data on the Time 1 EOM-EIS-II scales did not differ in age, sex, socioeconomic status, or mean levels of the goal 
Table 1 Content analysis of goals at age 18

\begin{tabular}{|c|c|c|c|}
\hline Focus of education goal description & $\%$ & Focus of work goal description & $\%$ \\
\hline Getting high grades & 18.6 & $\begin{array}{l}\text { Working in a specific field, industry, institution, or } \\
\text { profession }\end{array}$ & 20.9 \\
\hline Getting bachelor's degree & 17.8 & $\begin{array}{l}\text { Working in a job/career that is truly rewarding or } \\
\text { exciting }\end{array}$ & 10.1 \\
\hline Getting graduate/professional degree & 17.8 & $\begin{array}{l}\text { Working in a job/career that is both rewarding and } \\
\text { lucrative }\end{array}$ & 7.0 \\
\hline Learning and self-discovery & 10.9 & Getting/keeping any job & 6.2 \\
\hline $\begin{array}{l}\text { Using college/university as a stepping stone to a better col- } \\
\text { lege/university, career, or lifestyle }\end{array}$ & 9.3 & Succeeding at a job/career and building a network & 5.4 \\
\hline $\begin{array}{l}\text { Improving skills (e.g., time management, concentration, } \\
\text { financial, work-life balance) }\end{array}$ & 3.9 & Artistic, literary, or research production & 5.4 \\
\hline Extra-curricular activities and study abroad & 3.9 & $\begin{array}{l}\text { Explore and learn about career opportunities before } \\
\text { deciding what to pursue }\end{array}$ & 5.4 \\
\hline Fluency in foreign language/s & 3.9 & $\begin{array}{l}\text { Getting a steady job right after college/university } \\
\text { graduation }\end{array}$ & 4.7 \\
\hline Getting into college/university & 2.3 & Community or civic contribution & 4.7 \\
\hline Adjusting to college/university life & 2.3 & Working in a job/career that is lucrative & 3.9 \\
\hline Community contribution/advocacy & 2.3 & Entrepreneurship/running my own business & 3.9 \\
\hline Graduating from high school & 1.6 & Improving job-related competencies & 3.9 \\
\hline Getting technical/vocational school certificate & 1.6 & $\begin{array}{l}\text { Working to pay tuition, loans, expenses while in } \\
\text { college/university, amass savings }\end{array}$ & 3.9 \\
\hline \multirow[t]{5}{*}{ Other } & \multirow[t]{5}{*}{3.9} & Getting a summer job & 3.9 \\
\hline & & Getting a college/university degree & 2.3 \\
\hline & & $\begin{array}{l}\text { Gaining work experience while in college/univer- } \\
\text { sity }\end{array}$ & 1.6 \\
\hline & & Hold elected office & 1.6 \\
\hline & & Other & 5.4 \\
\hline
\end{tabular}

$\%=$ Percentage of participants whose work goal description fit this focus. Goal descriptions classified as "Other" could not be grouped with any other descriptions

appraisal or motivational qualities indices. Likewise, participants who were missing vs. not missing data on the Time 2 EOM-EIS-II scales did not differ in age, sex, or mean levels of the two goal indices but had slightly lower scores on the Hollingshead Four-Factor Index of Socioeconomic Status $(t(107)=-2.20, p=.030)$. Given that measurement points in this study spanned a 5-year period characterized by instability and change (i.e., the first half of emerging adulthood), the most likely explanation for these missing data is participant attrition. Based on these considerations and the fact that the pattern of missing data gave us no reason to suspect that missingness was related to the missing values themselves, we retained the assumption that the data were missing at random (MAR; Rubin, 1976).

\section{Exploratory Mixed-Methods Analysis of Ideographic Education and Work Goals at Age 18}

\section{Goal Contents at Age 18}

Participants described a diverse array of education goals (Table 1). Over a third of education goals focused on the completion of a technical certificate or bachelor's, master's, or doctoral/professional degree. In addition, $18.6 \%$ focused on getting good grades, $10.9 \%$ on learning and self-discovery, and $9.3 \%$ on using college/university as a stepping stone to an imagined future (e.g., a better educational institution, a career, or a lifestyle). Smaller groups of participants described experiences (e.g., study abroad, extra-curricular activities) and competencies (e.g., foreign language acquisition, improved time management and concentration) they wished to acquire in university, as well as transition goals (e.g., adjusting socially to life in university), goals for community contribution and advocacy, and diverse others. 
Participants also described a diverse array of work goals (Table 1). For example, whereas $20.9 \%$ of participants described goals to work in a specific company, field, industry, or profession, a similar (combined) percentage described goals to receive specific kinds of rewards from whatever work they ended up pursuing, such as financial rewards (3.9\%), happiness and excitement $(10.1 \%)$, or both $(7.0 \%)$. Smaller numbers of participants described goals that would require high degrees of personal agency (e.g., entrepreneurship, artistic, literary, or research production, exploration of career possibilities while in university). Still other descriptions reflected a focus on successful entry into the labor market following school (e.g., success and network-building, improving job-related competencies, gaining work experience during university, and securing full-time employment immediately after graduation).

\section{Goal Appraisals at Age 18}

Distributional statistics for the goal appraisals are reported in Table 2. Inspection of modal scores indicated that the greatest proportion of participants appraised their education goals as highly important and themselves as highly knowledgeable, capable, and well-equipped (e.g., possessing the means) vis-à-vis their goal pursuit. In addition, the greatest proportion of participants appraised their level of involvement and likelihood of achieving their education goal quite highly, although the modal scores for these dimensions did not reach the top available rating. Finally, results revealed multiple modes for the dimension of success, with the greatest proportions of participants appraising themselves as "somewhat (3)" successful so far vis-à-vis their education goal or choosing the second-to-highest value (5) to describe their success. Modal scores for work goals were identical to those for education goals except for the success appraisal. Whereas there were two modes for success appraisals of education goals, results revealed only one for work goals. The greatest proportion of participants reported that they had had "some (3)" success vis-à-vis their work goal at the time of the study. Inspection of median scores for education and work goal appraisals revealed a pattern within and across goals that was nearly identical to that obtained for the modal scores. However, mean appraisal scores for both goals fell generally at or, in most cases, below the median and the mode for the different dimensions.

\section{Motivational Qualities of Goals at Age 18}

Table 3 presents results of our qualitative analysis of mastery goals, autonomous motivation, intrinsic content, volitional phrasing, and distal temporal framing in participants' education and work goal descriptions, as well as operational definitions for each target construct and examples of descriptions in which each construct was coded as present (i.e., assigned a code of 1). Chi-square tests of independence indicated that gender was unrelated to code frequencies for both education and work goals.

Educational Goals Regarding mastery goals, $27.9 \%$ of goal descriptions contained text that reflected gaining knowledge and/or mastering challenges, according to the achievement goals framework (e.g., "To become fluent in the Japanese language"). Regarding autonomous motivation, a similar percentage $(23.3 \%)$ of goal descriptions explicitly reflected personal values, interest, or pleasure (e.g., "I would just like to go to Berkeley and immerse myself in the college life. I want to find out what I enjoy the most, and then learn what I can about anything and everything that piques my interests...”). In contrast, almost all of the 129 education goal descriptions could be coded as intrinsic in content. Some could be coded as intrinsic because they could be classified within the domains of personal growth (e.g., "Show that I am able to concentrate in order to complete my work so I can go through first semester with flying colors"), or community contribution (e.g., "I worked at Sibley Memorial Hospital in the ER for 2 years as a volunteer. I started out doing it for school junior year, but I continued it through the summer and until the end of senior year."). Others could be coded as intrinsic because they seemed likely to satisfy a basic psychological need for competence in the developmental context of early EA (e.g., "Graduating from automotive tech school," "...I want to manage my time well and stay on top of my school work."). Almost all (91.5\%) of education goal descriptions were phrased in an unembellished, volitional manner. About a quarter (26.4\%) referred to time after university studies had been completed.

Work Goals As shown in Table 3, a little over a quarter of work goal descriptions (26.4\%) were coded for mastery goals (e.g., "I want to progress in a career that stimulates, challenges, and satisfies me."). Regarding autonomous motivation, $48.8 \%$ of goal statements explicitly reflected personal values (e.g., "...I would love to be a doctor and bring medical assistance to those lacking proper health care, especially in countries that lack sustainable infrastructure."), interest (e.g., "To eventually create my own manga (Japanese style comics) series"), or pleasure (e.g., "I hope to be happy and successful in whatever career I choose"). Finally, almost all work goal statements could be coded as intrinsic in content because they fell within one of the prototypical domains (e.g., community contribution; e.g., "Get a job that really helps others going through teenage anxiety issues") or seemed likely to instill a sense of competence (e.g., "I'd like to find an entry level position in the music industry"), when competence was conceptualized in the context of having recently graduated from university. Approximately $85 \%$ of 
work goal descriptions were phrased in an unembellished, volitional manner and $59.7 \%$ referred to the time after university studies were completed.

\section{Effects of Goal-Related Constructs at Age 18 on Dimensions of Identity Development at Ages 18 and 23}

As shown in Table 4, the goal appraisals index was correlated with higher levels of concurrent identity achievement, whereas the motivational qualities index was correlated with higher levels of concurrent identity achievement and lower levels of moratorium, foreclosure, and diffusion. In contrast, the appraisal index was correlated with higher levels of Time 2 identity achievement and lower levels of moratorium and diffusion, whereas the motivational qualities index was correlated only with lower levels of Time 2 diffusion. In addition, correlations revealed medium-to-high levels of rankorder stability for the identity dimensions between ages 18 and 23 (correlations ranging from $r=.36$ to $r=.69$ ).

To test the hypothesis that both indices would be positively related to dimensions of identity development that also reflect potentials for intentional self-development (i.e., achievement and moratorium), and negatively related to dimensions that reflect difficulties with, or barriers to intentional self-development (i.e., foreclosure and diffusion), both concurrently (at age 18) and prospectively (at age 23), we conducted a series of eight multiple regression analyses. Into the first four equations, which predicted levels of concurrent (Time 1) identity achievement, moratorium, foreclosure, and diffusion, respectively, we entered gender, SES, and education and work goal word count as covariates and the goal appraisals and motivational qualities indices as the predictors of interest. Results (Table 5) indicated that gender, SES, and word count were unrelated to the four age 18 identity outcomes. The appraisals index predicted higher levels of concurrent identity achievement but was unrelated to moratorium, foreclosure, and diffusion. In contrast, the motivational qualities index predicted higher levels of concurrent identity achievement and lower levels of concurrent identity moratorium and diffusion, but was unrelated to concurrent identity foreclosure.

Into the second four equations, which predicted levels of identity achievement, moratorium, foreclosure, and diffusion at age 23 (Time 2), respectively, we entered the same set of predictors as well as Time 1 levels of each identity outcome. Results (Table 5) indicated that the covariates were unrelated to change in the identity outcomes, with the exception that higher SES predicted increases in identity achievement and decreases in identity moratorium from ages 18 to 23 . The appraisals index predicted 5-year increases in identity achievement, 5-year decreases in identity moratorium and diffusion, and no statistically significant change in levels of identity foreclosure. In contrast, the motivational qualities index was unrelated to change in any of the identity outcomes.

\section{Discussion}

Intentional self-development refers to the capacity of human beings to shape the course of their own development through goal-directed action, evolving mental representations of self and environment, and reciprocal influences between these processes over time (Brandtstädter, 2009). We have proposed that capacities for intentional self-development should help individuals to optimize their own development during EA. Specifically, emerging adults who exercise capacities for intentional self-development should be more likely to take advantage of time-limited opportunities to explore and more likely to steer the course of their own lives in valued directions during a lifespan phase that offers few normative guidelines for development. If this is the case, then identifying mechanisms of intentional self-development during EA is an important task for developmental science. A growing body of research indicates that processes of goal striving and processes of identity development that reflect potentials for intentional self-development in EA are interrelated and may influence one another positively as emerging adults navigate the transition to adulthood. The present study aimed to contribute to this nascent literature by exploring the ways in which the ideographic goals of emerging adults reflect potentials for intentional self-development and providing longitudinal evidence for effects of goal-related constructs that reflect these potentials on kindred processes of identity development over time.

The results of our exploratory, mixed-methods analysis revealed diversity in the foci of the ideographic education and work goals of European American high school seniors on the cusp of EA, strong potentials for intentional selfdevelopment reflected in their appraisals of these goals, and more complex reflections of intentional self-development in the motivational qualities we coded from their goal descriptions. Results of multiple regression analyses partially supported the hypothesis that the goal appraisals and motivational constructs we explored would predict kindred self-intentional processes of identity development across the first 5 years of EA. Here, we discuss the theoretical implications of the findings, as well as their implications for future research aimed at identifying the mechanisms of intentional self-development in EA. 


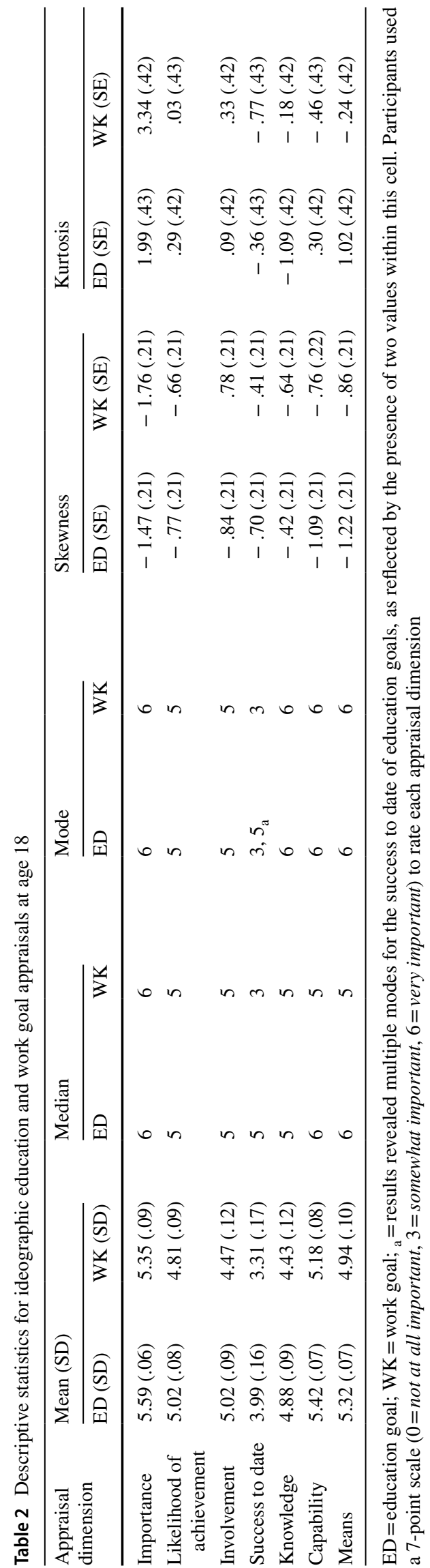

\section{Potentials for Intentional Self-development in Ideographic Education and Work Goals at Age 18}

As expected, our exploratory analysis of the most important goals of European American high school seniors revealed rich, nuanced descriptive results that raised interesting questions for future research. First, the seniors in our sample appraised their education and work goals in ways that reflected strong potentials for intentional self-development in EA.Participants consistently appraised both their goals as highly important and themselves as highly knowledgeable, capable, involved, well-equipped for success, and likely to succeed. Regarding appraisals of success to date, participants' ratings indicated a clear-eyed objectivity concerning personal progress, with wide variation in ratings for education goals and varied, but notably lower, ratings for work goals (which is understandable given the distal nature of most of those goals from age 18). Overall, these findings align with Arnett's characterization of EA as a period marked by optimism (Arnett, 2000; Arnett \& Schwab, 2013) and indicate that appraisals of goal pursuits linked to beliefs of importance and attainability may be potential mechanisms for intentional self-development as emerging adults transition to adulthood.

An additional implication of the high degree of consistency in appraisal ratings observed both within and across education and work goals in this sample is that individuals may begin EA with relatively uniform beliefs concerning goal importance and attainability but become more differentiated with respect to these beliefs as they initiate and complete action cycles aimed at goal achievement in different domains (i.e., cycles of goal selection, engagement, and disengagement from blocked or unattainable goals; Heckhausen et al., 2010). While not the focus of the present study, future research could test this interpretation by collecting appraisals for education and work goals at multiple measurement points across EA and measuring the degree to which changes in appraisal ratings correspond to changes in emerging adults' action phase of goal pursuit.

In contrast, the seniors in our sample described their goals in ways that reflected strong potentials for intentional self-development associated with certain motivational constructs, lower potentials for intentional self-development associated with other motivational constructs, and some interesting contrasts between code frequencies for education vs. work goals. Specifically, qualitative coding of motivational constructs across goal descriptions revealed (i) a high frequency of intrinsic goal content and volitional phrasing across education and work goals, (ii) a lower frequency of autonomous motivation and mastery goals across education and work goals, (iii) a higher frequency of autonomous motivation in work goal descriptions than in education goal descriptions, and (iv) a higher frequency of distal temporal 


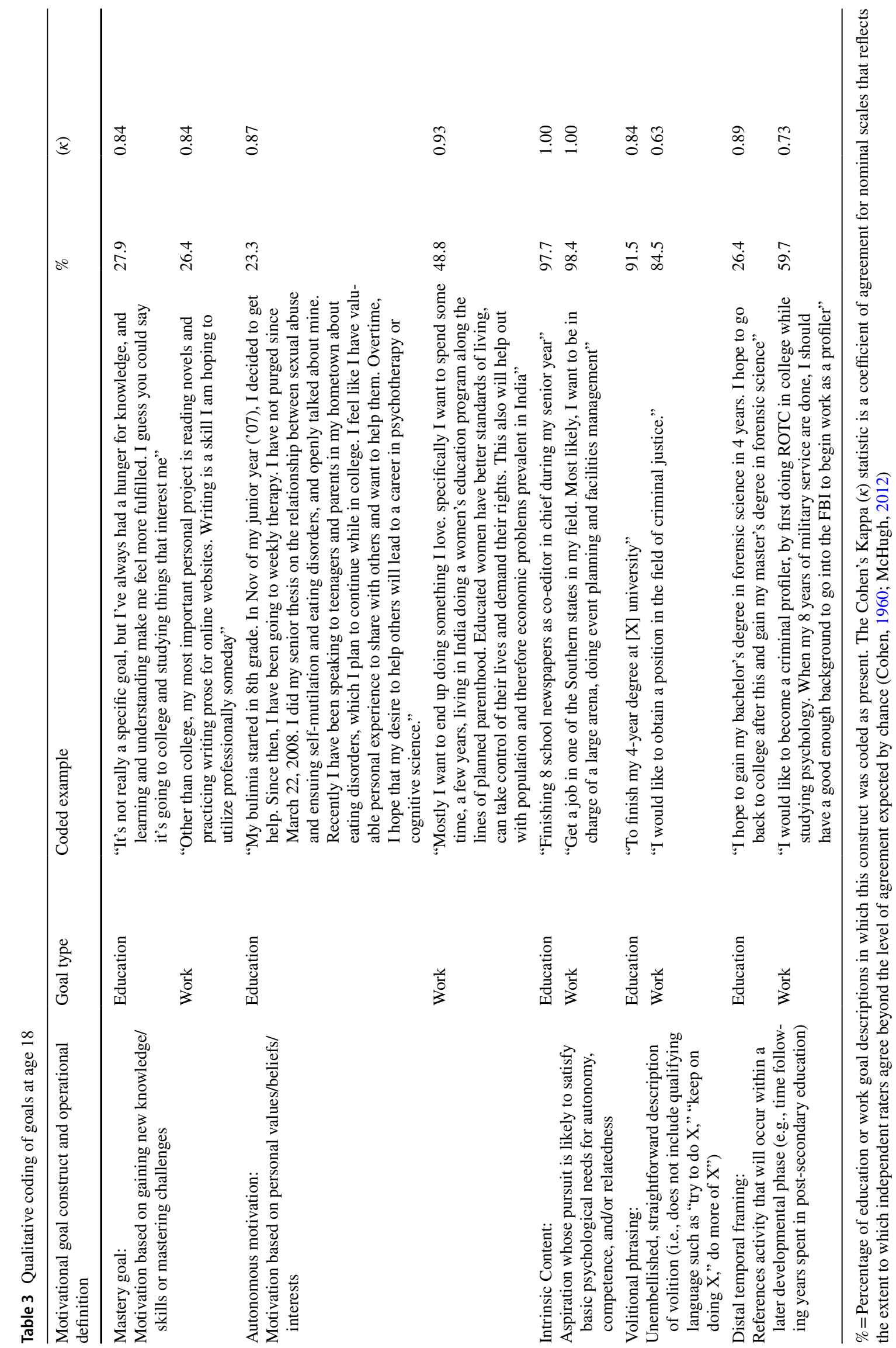


framing in work goal descriptions than in education goal descriptions. In the present study, we chose to code goal descriptions for each of these motivational constructs on the basis of their theoretical and empirical links to autonomous motivation and basic psychological need satisfaction, which, in turn, can be conceptualized as factors that promote assimilative activities of intentional self-development in EA. If our rationale for these choices was correct, then what can account for the inconsistency in code frequencies both within and across goal descriptions we observed?

One interpretation of this pattern of code frequencies is that our coding scheme underestimated the extent to which participants' ideographic education and work goals reflected autonomous motivation and mastery goals at age 18. Previous research indicates that qualitative coding of ideographic narratives for SDT-based constructs can be reliable, valid, and predictive of relevant developmental outcomes. For example, Philippe et al. (2011) showed that narratives of emerging adults' self-defining memories could be reliably coded for levels of basic psychological need satisfaction, that narrative codes for basic psychological need satisfaction were positively correlated with self-report ratings of basic psychological need satisfaction for the same memories $(r=.70)$, and that coded and self-reported need satisfaction in memories predicted well-being and psychological adjustment in a virtually identical fashion. In this study, participants were prompted to describe in detail memories of important events that "reflect your identity or who you are and should reveal something about how you perceive yourself generally (p. 912)." In contrast, the European American high school seniors who completed the PPA for the present study were prompted to describe their most important education and most important work goal, with no instructions concerning level of detail, identity, or personal expressiveness. Therefore, it is possible that instructions that prompt emerging adults to reflect deeply on themselves and their identities are necessary to elicit goal descriptions in which autonomous motivation and mastery goals, when present, are clearly emergent, a possibility that awaits confirmation in future research.

Alternatively, however, lower frequencies of autonomous motivation and mastery goals across participants' ideographic education and work goals may reflect discouraging realities of U. S. American educational contexts. Past research has shown that factors such as rewards, evaluations, deadlines, and observation - each of which features prominently in North American school settings-are associated with declines in self-determined forms of motivation over time (Deci \& Ryan, 1980, 2000). To clarify which interpretation is more valid, future replication studies could compare results of qualitative coding of goal descriptions with selfreport ratings of autonomous motivation and mastery goals.
Last, the higher frequency of autonomous motivation codes among work vs. education goals could also reflect the controlling forces that U. S. American students perceive in secondary school contexts (Vallerand et al., 1997). Perhaps, in thinking about their more distal work goals, participants imagined fewer of the controls associated with educational institutions and more opportunities for choice, freedom, and self-determination, another possibility that could be tested in future research.

\section{Effects of Goal Appraisals and Motivational Qualities on Dimensions of Identity Development in EA}

The second aim of the present study was to test the hypothesis that goal-related constructs associated with intentional self-development would promote kindred processes of identity development across the first five years of EA. To this end, we summed appraisal ratings and motivational construct codes across participants' most important education and work goals to create two composite scores for use in bivariate correlation and multiple regression analyses. Results revealed that these composite scores each independently predicted multiple dimensions of identity development, both concurrently and prospectively, but not always as expected.

We hypothesized that intentional self-development as manifested in goals would be an important antecedent of dimensions of identity development that are rooted in exploration and that, therefore, we would observe positive effects of both our composite scores on identity achievement and moratorium. Regarding identity achievement, results generally supported this hypothesis; the indices for goal appraisals and motivational qualities were both positive predictors of concurrent identity achievement and the overall score for appraisals predicted increases in achievement over five years. These findings align with the idea that appraisals and motivational qualities that promote assimilative activities of intentional self-development are assets that support identity commitments anchored in previous exploration. Simply put, the more emerging adults' goal appraisals and motivational qualities reflect potentials for intentional self-development during a life stage that provides little guidance and support for individual striving (Schwartz et al., 2005), the more likely they may be to take advantage of time-limited opportunities to explore, to search for identity "fit" in their education and work, and to adhere to commitments made on the basis of the self-knowledge and information they have gained.

Unexpectedly, the indices for goal appraisals and motivational qualities were negatively associated with concurrent and subsequent levels of identity moratorium, respectively. We suggest that these findings may reflect how moratorium is operationalized by the EOM-EIS-II. The moratorium 
Table 4 Bivariate correlations between appraisals index, motivational qualities index, and dimensions of identity development at ages 18 and 23

\begin{tabular}{|c|c|c|c|c|c|c|c|c|c|c|}
\hline & 1. & 2. & 3. & 4. & 5. & 6. & 7. & 8. & 9. & 10. \\
\hline \multicolumn{11}{|l|}{ 1. Appraisals index } \\
\hline 2. Motivation index & .02 & & & & & & & & & \\
\hline 3. Achievement (18) & $.24^{*}$ & $.24 * *$ & & & & & & & & \\
\hline 4. Moratorium (18) & -.13 & $-.23 * *$ & $-.46^{* *}$ & & & & & & & \\
\hline 5. Foreclosure (18) & -.00 & $-.19 *$ & .01 & $.19^{*}$ & & & & & & \\
\hline 6. Diffusion (18) & -.18 & $-.27 * *$ & $-.39 * *$ & $.52 * *$ & $.23^{*}$ & & & & & \\
\hline 7. Achievement (23) & $.30 * *$ & .16 & $.36^{* *}$ & $-.37 * *$ & -.07 & $-.25^{*}$ & & & & \\
\hline 8. Moratorium (23) & $-.34 * *$ & -.09 & $-.25^{*}$ & $.63 * *$ & .14 & $.41 * *$ & $-.55 * *$ & & & \\
\hline 9. Foreclosure (23) & .00 & -.16 & .06 & .17 & $.69 * *$ & .13 & $-.27 * *$ & $.25^{*}$ & & \\
\hline 10. Diffusion (23) & $-.21 *$ & $-.25 * *$ & $-.28 * *$ & $.33 * *$ & .16 & $.64 * *$ & $-.41 * *$ & $.40 * *$ & .03 & \\
\hline
\end{tabular}

$N=129$. Appraisals index $=$ sum of seven goal appraisals (importance, likelihood of accomplishment, depth of involvement, success to date, knowledge of how to achieve the goal, capacity to achieve the goal, and having the means to achieve the goal) across education and work goals; Motivation index = sum of motivational construct codes (mastery goal, autonomous motivation, intrinsic content, volitional phrasing, and distal temporal framing) across education and work goals; Achievement (18)-Diffusion (18) = self-rated dimensions of identity development at age 18; Achievement (23)-Diffusion (23) = self-rated dimensions of identity development at age 23

$* p<.05 . * * \leq .01$

subscale of the EOM-EIS-II reflects Marcia's (1966) original conceptualization of moratorium as exploration in the absence of commitments. Theoretical and empirical evidence has subsequently emerged for the existence of a "searching" moratorium, a form of exploration that is anchored in pre-existing commitments (Crocetti et al., 2008a, 2008b). Intentional self-development driving goal pursuit is likely to result in more, rather than less, engagement with ongoing educational and occupational commitments, thus providing a solid foundation from which to explore. Future research that examines associations between goal-related constructs and contemporary, process-oriented conceptualizations of exploration (e.g., exploration in breadth, exploration in depth, searching moratorium, ruminative exploration, etc.) are needed to explore this finding in greater depth.

Third, we expected that goal-related constructs reflecting intentional self-development would be negatively related to dimensions of identity development that reflect a lack of exploration-namely, identity foreclosure and identity diffusion. We found support for this hypothesis at the bivariate level for the motivational qualities index and identity foreclosure and diffusion at age 18 , and to a lesser extent at age 23. The appraisals index was not related to foreclosure and less strongly associated with diffusion than the motivational qualities index. These patterns held in regression analyses but the effect sizes were smaller. It is important to note that in the present study, we investigated the effects of goal-related constructs that reflect potentials for intentional self-development, as opposed to difficulties with, or threats to intentional self-development. Results of the present study indicate that future studies may need to include such indicators (e.g., appraisals of failure or incompetence, qualitative codes/ratings for controlled motivation and extrinsic goal content; Deci \& Ryan, 2000) in order to improve the prediction of dimensions like identity foreclosure and diffusion, or processes like ruminative exploration (Luyckx et al., 2008).

\section{Strengths, Limitations, and Future Directions}

To our knowledge, the present study is the first to explore the ways in which the ideographic goal descriptions and appraisals of emerging adults reflect potentials for intentional self-development, an exercise that revealed new and nuanced information concerning these goals and generated avenues for future research. Likewise, this is the first study to investigate associations between goal-related constructs that reflect potentials for intentional self-development and kindred dimensions of identity development across a substantial span of EA, an exercise that contributed needed support for the idea that goal-related constructs may influence dimensions of identity development across this lifespan phase.

These strengths notwithstanding, our analyses were conducted using an ethnically homogeneous but socioeconomically heterogeneous (but not low SES) sample, specifying, but also limiting, the generalizability of the results to European American emerging adults from middle- to high-SES families. Previous research has shown that both SES and ethnicity influence the educational and career aspirations of U.S. American youth. For example, in a large study $(N=22,136)$ of Midwestern middle and high school students, lower-SES students reported lower career aspirations as indexed by lower levels of prestige, lower minimum level of education, and lower median income. Moreover, whereas there were no differences in career aspirations 





among European American, African American, Asian/ Pacific Islander, and Latino/x students, Native American students reported lower career aspirations, with low-SES Native American students reporting the lowest aspirations (Howard et al., 2011). Other research, however, has shown that career aspirations do not differ on average across ethnic groups (Chang et al., 2006). Perhaps U. S. American youth with different ethnic self-identifications hold similar understandings about the means by which one achieves success and independence in the United States, understandings that may be linked to the pursuit of upward economic mobility associated with the "American Dream." But, for lower-SES emerging adults, opportunities to pursue that dream are significantly constrained (e.g., Bay-Cheng \& Zucker, 2017; Raposa et al., 2018). Additionally, for Native American youth, the pursuit of the "American Dream" may conflict with ethnic identity because the American Dream is inextricably linked to colonization. Indeed, future research with multi-ethnic samples should examine aspects of ethnic identity that may moderate processes of intentional self-development in EA. For example, if emerging adults self-identify with ethnic groups that value community and family relationships (e.g., Sánchez et al., 2010), these values may manifest in their processes of goal striving and identity development in ways that differ from those of emerging adults from ethnic groups that valorize individualism. Similarly, geographic region can influence perceptions of mobility and create conflicts between goals if pursuing education and career paths require youth to move away from home (Brooks \& Redlin, 2009). To provide the fullest picture of how goal processes, identity processes, and their associations over time serve as mechanisms for intentional self-development in EA, future research should recruit samples that are diverse with respect to region, ethnicity, culture, and socioeconomic resources, as well as other factors that intersect with goals and identity, to enable cross-group comparisons.

Additionally, the EOM-EIS-II, which operationalizes identity development according to Marcia's (1966) original status model, does not reflect subsequent shifts towards process-oriented and dynamic perspectives in the field of identity development (Crocetti \& Meeus, 2015; Schwartz et al., 2015). The fact that internal consistency values for some EOM-EIS-II subscales in our samples were low in magnitude ( $\alpha \mathrm{s}<.70$ for achievement and diffusion) may be indicative of this limitation. Finally, previous theoretical and empirical work suggest that goal and identity processes are interrelated and may influence one another during EA (e.g., Luyckx et al., 2017; Marttinen et al., 2018; Shulman \& Nurmi, 2010). We investigated concurrent and prospective effects of goal-related constructs on dimensions of identity development, but not vice versa, offering only a partial account of the association between these phenomena in EA. In addition to addressing future directions noted above, future research could address these limitations by investigating concurrent and prospective associations among goal-related constructs and dimensions of identity development (i) in conjunction with contemporary processoriented identity development measures and (ii) by relying on statistical approaches that allow researchers to explore the directionality of effects, such as cross-lagged panel models (e.g., Luyckx et al., 2017). In addition, future research could investigate potential moderators of the effects of goalrelated constructs on dimensions of identity development across EA, such as cognitive development and additional contextual effects that influence opportunities for intentional self-development (e.g., economic changes associated with the COVID-19 pandemic in the United States).

\section{Contributions to the Study of Intentional Self-Development in EA}

The present study provides nuanced descriptive information concerning the extent to which emerging adults' most important goals reflect potentials for intentional self-development, contributes to the growing literature linking goal-related constructs and dimensions of identity development in EA, and suggests numerous avenues for future research. Particularly intriguing is the possibility that goal-related constructs that reflect intentional self-development may support and promote kindred processes of identity development, which, in turn, promote the selection of goals whose appraisals and motivational qualities help emerging adults to optimize their developmental potentials across the third decade of life. Such an upward spiral is consistent with Brandtstädter's (2009) contention that reciprocal influences between goal-direction action and evolving mental representations of self and environment are key mechanisms of intentional self-development and could constitute an important pathway to healthy development across EA.

Supplementary Information The online version contains supplementary material available at https://doi.org/10.1007/s10804-021-09386-0.

Acknowledgements Charlene Hendricks contributed to the design and conceptualization of this study and provided feedback on earlier drafts of the manuscript, but passed away before its completion. We thank her for her essential contributions to this work.

Author Contributions Not applicable.

Funding The first author's work was supported by fellowships from the Social Sciences and Humanities Research Council of Canada and the Fonds de recherche du Québec-Société et Culture. This research was supported by the Intramural Research Program of the NIH/NICHD, USA (Z99 HD999999) and an International Research Fellowship at the Institute for Fiscal Studies, London, UK, funded by the European Research Council under the Horizon 2020 research and innovation programme (Grant Agreement No. 695300-HKADeC-ERC-2015-AdG). 
Data Availability The raw data contained in this manuscript are not openly available due to the fact that consent to sharing data was not obtained from participants at the time of data collection. The analysis code/syntax used for analyses are not openly available but are available upon request to the corresponding author following the completion of a privacy and fair use agreement. The operational definitions used for the content analysis of goal descriptions in the present study are provided in tables within the main manuscript text. The simple presence/ absence coding scheme is explained in detail in the text and illustrated with examples in tables within the manuscript. All other materials (e.g., widely used self-report measures) used in the present study are publically available. No aspects of the study were pre-registered.

Code Availability Not applicable.

\section{Declarations}

Conflict of interest The authors declare that they have no conflict of interest.

Ethical Approval Data analyzed in this study were part of an IRB-approved research study conducted at the Eunice Kennedy Shriver National Institute of Child Health and Human Development.

Consent to Participate Participants consented to participate in the study at ages 18 and 23 years. The age 18 consent form is attached to this submission as a supplementary file. The study number has been blinded for this submission.

Consent for Publication All co-authors consented to this submission via email. All participants consented to publication of results in health sciences journals.

\section{References}

Adams, J., \& Weakliem, D. L. (2011). August B. Hollingshead's "Fourfactor index of social status": From unpublished paper to citation classic. Yale Journal of Sociology, 8, 11-20.

Ames, C., \& Archer, J. (1988). Achievement goals in the classroom: Students' learning strategies and motivation processes. Journal of Educational Psychology, 80(3), 260-267. https://doi.org/10. 1037/0022-0663.80.3.260

Arnett, J. J. (2000). Emerging adulthood: A theory of development from the late teens through the twenties. American Psychologist, 55(5), 469-480. https://doi.org/10.1037/0003-066X.55.5.469

Arnett, J. J. (2014). Presidential address: The emergence of emerging adulthood: A personal history. Emerging Adulthood, 2(3), 155-162. https://doi.org/10.1177/2167696814541096

Arnett, J. J., \& Schwab, J. (2013). The Clark University Poll of Emerging Adults, 2012: Thriving, struggling, and hopeful. Clark University.

Asparouhov, T., \& Muthén, B. O. (2010). Weighted least square estimation with missing data (Mplus Technical Appendix). Muthén \& Muthén.

Bachman, R. D., \& Schutt, R. K. (2013). The practice of research in criminology and criminal justice. Sage Publications Inc.

Bay-Cheng, L. Y., \& Zucker, A. N. (2017). What the future holds: The goals of emerging adult women at three socioeconomic locations. Emerging Adulthood, 5(5), 351-356. https://doi.org/10. $1177 / 2167696817695134$

Bennion, L. D., \& Adams, G. R. (1986). A revision of the extended version of the Objective Measure of Ego Identity Status: An identity instrument for use with late adolescents. Journal of Adolescent Research, 1(2), 183-197. https://doi.org/10.1177/0743554886 12005

Berzonsky, M. D. (1989). Identity style: Conceptualization and measurement. Journal of Adolescent Research, 4(3), 268-282. https:// doi.org/10.1177/074355488943002

Bornstein, M. H., Jager, J., \& Putnick, D. L. (2013). Sampling in developmental science: Situations, shortcomings, solutions, and standards. Developmental Review, 33(4), 357-370. https://doi.org/10. 1016/j.dr.2013.08.003

Bornstein, M. H., Putnick, D. L., \& Suwalsky, J. T. (2019). Motherinfant interactions with firstborns and secondborns: A within-family study of European Americans. Infant Behavior and Development, 55, 100-111. https://doi.org/10.1016/j.infbeh.2019.03.009

Brandtstädter, J. (1999). The self in action and development: Cultural, biosocial, and ontogenetic bases of intentional self-development. In J. Brandtstädter \& R. M. Lerner (Eds.), Action \& self-development: Theory and research through the life span (pp. 37-65). Sage Publications Inc. https://doi.org/10.4135/9781452204802.n2

Brandtstädter, J. (2009). Goal pursuit and goal adjustment: Self-regulation and intentional self-development in changing developmental contexts. Advances in Life Course Research, 14(1-2), 52-62. https://doi.org/10.1016/j.alcr.2009.03.002

Brandtstädter, J., \& Lerner, R. M. (1999). Action, development, and intentionality. In J. Brandtstädter, \& R. M. Lerner (Eds.), Action \& self-development: Theory and research through the life span (pp. ix-xvii). Sage Publications, Inc.

Brandtstädter, J., \& Rothermund, K. (2002). The life course dynamics of goal pursuit and goal adjustment: A two-process framework. Developmental Review, 22(1), 117-150. https://doi.org/10.1006/ drev.2001.0539

Brandstätter, V., \& Herrmann, M. (2016). Goal disengagement in emerging adulthood: The adaptive potential of action crises. International Journal of Behavioral Development, 40(2), 117-125. https://doi.org/10.1177/0165025415597550

Brooks, W. T., \& Redlin, M. (2009). Occupational aspirations, rural to urban migration, and intersectionality: A comparison of white, black, and Hispanic male and female group chances for leaving rural counties. Journal of Rural Social Sciences, 24(1), 8.

Brunstein, J. C. (1993). Personal goals and subjective well-being: A longitudinal study. Journal of Personality and Social Psychology, 65(1), 1061-1070. https://doi.org/10.1037/0022-3514.65.5.1061

Cantor, N., Norem, J., Langston, C., Zirkel, S., Fleeson, W., \& CookFlannagan, C. (1991). Life tasks and daily life experience. Journal of Personality, 59(3), 425-451. https://doi.org/10.1111/j.14676494.1991.tb00255.x

Chambers, N. C. (2007). Just doing it: Affective implications of project phrasing. In B. R. Little, K. Salmela-Aro, \& S. D. Phillips (Eds.), Personal project pursuit: Goals, action and human flourishing (pp. 145-169). Lawrence Erlbaum \& Associates.

Chang, E. S., Chen, C., Greenberger, E., Dooley, D., \& Heckhausen, J. (2006). What do they want in life?: The life goals of a multi-ethnic, multi-generational sample of high school seniors. Journal of Youth and Adolescence, 35(3), 302-313. https://doi.org/10.1007/ s10964-006-9034-9

Cohen, J. (1960). A coefficient of agreement for nominal scales. Educational and Psychological Measurement, 20, 37-46. https://doi. org/10.1177/001316446002000104

Côté, J. E. (2002). The role of identity capital in the transition to adulthood: The individualization thesis examined. Journal of Youth Studies, 5(2), 117-134. https://doi.org/10.1080/136762602201344 03

Côté, J., \& Bynner, J. M. (2008). Changes in the transition to adulthood in the UK and Canada: The role of structure and agency in emerging adulthood. Journal of Youth Studies, 11(3), 251-268. https://doi.org/10.1080/13676260801946464 
Cote, L. R., Kwak, K., Putnick, D. L., Chung, H. J., \& Bornstein, M. H. (2015). The acculturation of parenting cognitions: A comparison of South Korean, Korean immigrant, and European American mothers. Journal of Cross-Cultural Psychology, 46(9), 1115-1130. https://doi.org/10.1177/0022022115600259

Crocetti, E., \& Meeus, W. (2015). The identity statuses: Strengths of a person-centered approach. In K. C. McLean \& M. Syed (Eds.), Oxford Library of Psychology. The Oxford handbook of identity development (pp. 97-114). Oxford University Press.

Crocetti, E., Rubini, M., Luyckx, K., \& Meeus, W. (2008a). Identity formation in early and middle adolescents from various ethnic groups: From three dimensions to five statuses. Journal of Youth and Adolescence, 37(8), 983-996. https://doi.org/10.1007/ s10964-007-9222-2

Crocetti, E., Rubini, M., \& Meeus, W. (2008b). Capturing the dynamics of identity formation in various ethnic groups: Development and validation of a three-dimensional model. Journal of Adolescence, 31(2), 207-222. https://doi.org/10.1016/j.adolescence. 2007.09.002

Crocetti, E., Sica, L. S., Schwartz, S. J., Serafini, T., \& Meeus, W. (2013). Identity styles, dimensions, statuses, and functions: Making connections among identity conceptualizations. European Review of Applied Psychology/Revue Européenne de Psychologie Appliquée, 63(1), 1-13. https://doi.org/10.1016/j.erap.2012. 09.001

Deci, E. L., \& Ryan, R. M. (1980). The empirical exploration of intrinsic motivational processes. In L. Berkowitz (Ed.), Advances in experimental social psychology (Vol. 13, pp. 39-80). Academic Press.

Deci, E. L., \& Ryan, R. M. (2000). The "what" and "why" of goal pursuits: Human needs and the self-determination of behavior. Psychological Inquiry, 11(4), 227-268. https://doi.org/10.1207/ S15327965PLI1104_01

Dietrich, J., Parker, P., \& Salmela-Aro, K. (2012). Phase-adequate engagement at the post-school transition. Developmental Psychology, 48(6), 1575-1593. https://doi.org/10.1037/a0030188

Elliot, A. J., \& McGregor, H. A. (2001). A $2 \times 2$ achievement goal framework. Journal of Personality and Social Psychology, 80(3), 501-519. https://doi.org/10.1037/0022-3514.80.3.501

Emmons, R. A. (1986). Personal strivings: An approach to personality and subjective well-being. Journal of Personality and Social Psychology, 51(5), 1058-1068. https://doi.org/10.1037/0022-3514. 51.5.1058

Erikson, E. H. (1950). Childhood and society. Norton.

Erikson, E. H. (1974). Dimensions of a new identity. Norton.

Erikson, E. H. (1980). Identity and the life cycle: A reissue. Norton.

Flunger, B., Marttinen, E., Tuominen-Soini, H., \& Salmela-Aro, K. (2016). How do young adults orchestrate their multiple achievement-related goals? Associations of achievement goal orientations with identity formation and goal appraisals. Research in Human Development, 13(4), 342-362. https://doi.org/10.1080/15427609. 2016.1234309

Heckhausen, J., \& Tomasik, M. J. (2002). Get an apprenticeship before school is out: How German adolescents adjust vocational aspirations when getting close to a developmental deadline. Journal of Vocational Behavior, 60(2), 199-219. https://doi.org/10.1006/ jvbe.2001.1864

Heckhausen, J., Wrosch, C., \& Schulz, R. (2010). A motivational theory of life-span development. Psychological Review, 117(1), 32-60. https://doi.org/10.1037/a0017668

Heckhausen, J., Chang, E. S., Greenberger, E., \& Chen, C. (2013). Striving for educational and career goals during the transition after high school: What is beneficial? Journal of Youth and Adolescence, 42(9), 1385-1398. https://doi.org/10.1007/ s10964-012-9812-5
Hollingshead, A. B. (1975). Four factor index of social status. Unpublished manuscript, Department of Sociology, Yale University.

Howard, K. A., Carlstrom, A. H., Katz, A. D., Chew, A. Y., Ray, G. C., Laine, L., \& Caulum, D. (2011). Career aspirations of youth: Untangling race/ethnicity, SES, and gender. Journal of Vocational Behavior, 79(1), 98-109. https://doi.org/10.1016/j.jvb.2010.12. 002

Jager, J., Putnick, D. L., \& Bornstein, M. H. (2017). Developmental methodology: More than just convenient: The scientific merits of homogeneous convenience samples. Monographs of the Society for Research in Child Development, 82, 13-30. https://doi.org/ 10.1111/mono.12296

Karasik, L. B., Tamis-LeMonda, C. S., Adolph, K. E., \& Bornstein, M. H. (2015). Places and postures: A cross-cultural comparison of sitting in 5-month-olds. Journal of Cross-Cultural Psychology, 46(8), 1023-1038. https://doi.org/10.1177/0022022115593803

Kasser, T., \& Ryan, R. M. (1996). Further examining the American dream: Differential correlates of intrinsic and extrinsic goals. Personality and Social Psychology Bulletin, 22(3), 280-287. https:// doi.org/10.1177/0146167296223006

Koestner, R., Otis, N., Powers, T. A., Pelletier, L., \& Gagnon, H. (2008). Autonomous motivation, controlled motivation, and goal progress. Journal of Personality, 76(5), 1201-1229. https://doi. org/10.1111/j.1467-6494.2008.00519.x

Lecci, L., Karoly, P., Briggs, C., \& Kuhn, K. (1994). Specificity and generality of motivational components in depression: A personal projects analysis. Journal of Abnormal Psychology, 103(2), 404408. https://doi.org/10.1037/0021-843X.103.2.404

Little, B. R. (1983). Personal projects: A rationale and method for investigation. Environment and Behavior, 15(3), 273-309. https:// doi.org/10.1177/0013916583153002

Little, B. R. (1989). Personal projects analysis: Trivial pursuits and magnificent obsessions, and the search for coherence. In D. Buss \& N. Cantor (Eds.), Personality psychology: Recent trends and emerging directions (pp. 15-31). Springer. https://doi.org/10. 1007/978-1-4684-0634-4_2

Little, B. R., \& Gee, T. L. (2007). The methodology of personal projects analysis: Four modules and a funnel. In B. R. Little, K. Salmela-Aro, \& S. D. Phillips (Eds.), Personal project pursuit: Goals, action, and human flourishing (pp. 51-94). Lawrence Erlbaum Associates Publishers.

Luyckx, K., Goossens, L., Soenens, B., \& Beyers, W. (2006). Unpacking commitment and exploration: Preliminary validation of an integrative model of late adolescent identity formation. Journal of Adolescence, 29(3), 361-378. https://doi.org/10.1016/j.adole scence.2005.03.008

Luyckx, K., Schwartz, S. J., Berzonsky, M. D., Soenens, B., Vansteenkiste, M., Smits, I., \& Goossens, L. (2008). Capturing ruminative exploration: Extending the four-dimensional model of identity formation in late adolescence. Journal of Research in Personality, 42(1), 58-82. https://doi.org/10.1016/j.jrp.2007.04.004

Luyckx, K., Duriez, B., Green, L. M., \& Negru-Subtirica, O. (2017). Identity processes and intrinsic and extrinsic goal pursuits: Directionality of effects in college students. Journal of Youth and Adolescence, 46(8), 1758-1771. https://doi.org/10.1007/ s10964-016-0626-8

Marcia, J. E. (1966). Development and validation of ego-identity status. Journal of Personality and Social Psychology, 3(5), 551-558. https://doi.org/10.1037/h0023281

Marttinen, E., Dietrich, J., \& Salmela-Aro, K. (2018). Intentional engagement in the transition to adulthood: An integrative perspective on identity, career, and goal developmental regulation. European Psychologist, 23(4), 311-323. https://doi.org/10.1027/ 1016-9040/a000337

McAdams, D. P., \& Olson, B. D. (2010). Personality development: Continuity and change over the life course. Annual Review of 
Psychology, 61, 517-542. https://doi.org/10.1146/annurev.psych. 093008.100507

McHugh, M. L. (2012). Interrater reliability: The kappa statistic. Biochemia Medica, 22(3), 276-282. https://doi.org/10.11613/bm. 2012.031

Milner, L. A., \& Ferrari, J. R. (2010). The role of goal orientation in emerging adult identity processing styles. Identity: An International Journal of Theory and Research, 10(4), 270-283. https:// doi.org/10.1080/15283488.2010.523645

Muthén, L. K., \& Muthén, B. O. (2017). Mplus user's guide. Muthén \& Muthén.

Negru, O., Pop, I. E., \& Opre, A. (2013). Foreshadowing identities: The relation between achievement goals and educational identity in a sample of Romanian emerging adults. Cognition, Brain, Behavior: An Interdisciplinary Journal, 17(1), 1-13.

Nelson, L. J., \& Barry, C. M. (2005). Distinguishing features of emerging adulthood: The role of self-classification as an adult. Journal of Adolescent Research, 20(2), 242-262. https://doi.org/10.1177/ 0743558404273074

Nurmi, J.-E. (1993). Adolescent development in an age-graded context: The role of personal beliefs, goals, and strategies in the tackling of developmental tasks and standards. International Journal of Behavioral Development, 16(2), 169-189. https://doi.org/10.1177/ 016502549301600205

Nurmi, J.-E. (2004). Socialization and self-development: Channeling, selection, adjustment and reflection. In R. Lerner \& L. Steinberg (Eds.), Handbook of adolescent psychology (pp. 85-124). Wiley.

Nurmi, J.-E., Salmela-Aro, K., \& Koivisto, P. (2002). Goal importance and related achievement beliefs and emotions during the transition from vocational school to work: Antecedents and consequences. Journal of Vocational Behavior, 60(2), 241-261. https://doi.org/ 10.1006/jvbe.2001.1866

Philippe, F. L., Koestner, R., Beaulieu-Pelletier, G., \& Lecours, S. (2011). The role of need satisfaction as a distinct and basic psychological component of autobiographical memories: A look at well-being. Journal of Personality, 79(5), 905-938. https://doi. org/10.1111/j.1467-6494.2010.00710.x

Putnick, D. L., Hahn, C. S., Hendricks, C., \& Bornstein, M. H. (2020). Developmental stability of scholastic, social, athletic, and physical appearance self-concepts from preschool to early adulthood. Journal of Child Psychology and Psychiatry, 61, 95-103. https:// doi.org/10.1111/jcpp. 13107

Raposa, E. B., Erickson, L. D., Hagler, M., \& Rhodes, J. E. (2018). How economic disadvantage affects the availability and nature of mentoring relationships during the transition to adulthood. American Journal of Community Psychology, 61(1-2), 191-203. https:// doi.org/10.1002/ajcp.12228

Rawsthorne, L. J., \& Elliot, A. J. (1999). Achievement goals and intrinsic motivation: A meta-analytic review. Personality and Social Psychology Review, 3(4), 326-344. https://doi.org/10.1207/s1532 7957pspr0304_3

Roberts, B. W., O’Donnell, M., \& Robins, R. W. (2004). Goal and personality trait development in emerging adulthood. Journal of Personality and Social Psychology, 87(4), 541-550. https://doi. org/10.1037/0022-3514.87.4.541

Ryan, R. M., \& Connell, J. P. (1989). Perceived locus of causality and internalization: Examining reasons for acting in two domains. Journal of Personality and Social Psychology, 57(5), 749-761. https://doi.org/10.1037/0022-3514.57.5.749

Ryan, R. M., \& Deci, E. L. (2017). Self-determination theory: Basic psychological needs in motivation, development, and wellness. Guilford.

Rubin, D. B. (1976). Inference and missing data. Biometrika, 63, 581-592.

Salmela-Aro, K. (2009). Personal goals and well-being during critical life transitions: The four C's-Channelling, choice, co-agency and compensation. Advances in Life Course Research, 14(1-2), 63-73. https://doi.org/10.1016/j.alcr.2009.03.003

Salmela-Aro, K., Aunola, K., \& Nurmi, J.-E. (2007). Personal goals during emerging adulthood: A 10-year follow up. Journal of Adolescent Research, 22(6), 690-715. https://doi.org/10.1177/07435 58407303978

Sánchez, B., Esparza, P., Colón, Y., \& Davis, K. E. (2010). Tryin' to make it during the transition from high school: The role of family obligation attitudes and economic context for Latino-emerging adults. Journal of Adolescent Research, 25(6), 858-884. https:// doi.org/10.1177/0743558410376831

Schwartz, S. J. (2001). The evolution of Eriksonian and neo-Eriksonian identity theory and research: A review and integration. Identity: An International Journal of Theory and Research, 1(1), 7-58. https://doi.org/10.1207/S1532706XSCHWARTZ

Schwartz, S. J., Côté, J. E., \& Arnett, J. J. (2005). Identity and agency in emerging adulthood: Two developmental routes in the individualization process. Youth \& Society, 37(2), 201-229. https:// doi.org/10.1177/0044118X05275965

Schwartz, S. J., Luyckx, K., \& Crocetti, E. (2015). What have we learned since Schwartz (2001)?: A reappraisal of the field of identity development. In K. C. McLean \& M. Syed (Eds.), Oxford Library of Psychology. The Oxford handbook of identity development (pp. 539-561). Oxford University Press.

Sheldon, K. M. (2014). Becoming oneself: The central role of self-concordant goal selection. Personality and Social Psychology Review, 18(4), 349-365. https://doi.org/10.1177/1088868314538549

Sheldon, K. M., Ryan, R. M., Deci, E. L., \& Kasser, T. (2004). The independent effects of goal contents and motives on well-being: It's both what you pursue and why you pursue it. Personality and Social Psychology Bulletin, 30(4), 475-486. https://doi.org/10. $1177 / 0146167203261883$

Shulman, S., \& Nurmi, J.-E. (2010). Understanding emerging adulthood from a goal-setting perspective. In S. Shulman \& J.-E. Nurmi (Eds.), New directions for child and adolescent development: 2010(130). The role of goals in navigating individual lives during emerging adulthood (pp. 1-11). Jossey-Bass. https://doi. org/10.1002/cd.277

Simons, J., Dewitte, S., \& Lens, W. (2004). The role of different types of instrumentality in motivation, study strategies, and performance: Know why you learn, so you'll know what you learn! British Journal of Educational Psychology, 74(3), 343-360. https:// doi.org/10.1348/0007099041552314

Sommet, N., \& Elliot, A. J. (2017). Achievement goals, reasons for goal pursuit, and achievement goal complexes as predictors of beneficial outcomes: Is the influence of goals reducible to reasons? Journal of Educational Psychology, 109(8), 1141-1162. https:// doi.org/10.1037/edu0000199

Tao, D., Zhang, R., Lou, E., \& Lalonde, R. N. (2018). The cultural shaping of career aspirations: Acculturation and Chinese biculturals' career identity styles. Canadian Journal of Behavioural Science/Revue Canadienne des Sciences du Comportement, 50(18), 29-41. https://doi.org/10.1037/cbs0000091

Vallerand, R. J., Fortier, M. S., \& Guay, F. (1997). Self-determination and persistence in a real-life setting: Toward a motivational model of high school dropout. Journal of Personality and Social Psychology, 72(5), 1161-1176. https://doi.org/10.1037/0022-3514. 72.5.1161

Vansteenkiste, M., Lens, W., Elliot, A. J., Soenens, B., \& Mouratidis, A. (2014). Moving the achievement goal approach one step forward: Toward a systematic examination of the autonomous and controlled reasons underlying achievement goals. Educational Psychologist, 49(3), 153-174. https://doi.org/10.1080/00461520. 2014.928598

Waterman, A. S. (2011). Eudaimonic identity theory: Identity as selfdiscovery. In S. J. Schwartz, K. Luyckx, \& V. L. Vignoles (Eds.), 
Handbook of identity theory and research (pp. 357-379). Springer Science + Business Media.

Weldon, E., \& Yun, S. (2000). The effects of proximal and distal goals on goal level, strategy development, and group performance. Journal of Applied Behavioral Science, 36(3), 336-344. https://doi. org/10.1177/0021886300363004
Publisher's Note Springer Nature remains neutral with regard to jurisdictional claims in published maps and institutional affiliations. 